\title{
Gene Expression Profiles of HIV/AIDS Patients with Qi-Yin Deficiency and Dampness-Heat Retention
}

\author{
Sa Liu, MS, ${ }^{1, *}$ Yulong Chen, MD, ${ }^{2, *}$ Shiping Xie, MD, Qianlei $X u, M D^{3}$ Jianshe Chen, MD, \\ Changhai Wang, MD, Zhao Wang, MD, Suna Ma, MS, Xingwei Wu, MS, and Ning Zhang, MS ${ }^{7}$
}

\begin{abstract}
Objectives: Traditional Chinese Medicine (TCM) applied in the clinic as a complementary and alternative therapy has helped improve immunity and reduce side effects and symptomatic treatment in patients with HIV/ AIDS. However, the mechanisms of TCM syndromes are not clear. Transcriptomics enables the study of such TCM syndromes.

Design: This study compared the messenger RNA (mRNA) expressions of healthy persons and patients with HIV/AIDS who had two common TCM syndromes, qi-yin deficiency and dampness-heat retention, to find the difference in HIV/AIDS with TCM syndromes.

Results: Comparison with healthy persons identified 113 mRNAs-41 enhanced and 72 decreased-in the qi-yin deficiency group. Additionally, 76 mRNAs were found in the dampness-heat retention group: 14 increased and 62 decreased. Functional genetic analysis of the mRNAs indicated that two TCM syndromes were correlated with cell apoptosis, immunoinflammatory responses, and lymphocyte activation. Differentially expressed mRNAs in the qi-yin deficiency group were obviously associated with cellular activity, communication, protein localization, cellular ion homeostasis, and regulation of cell motion, whereas mRNAs in the dampnessheat retention group were associated with sequence-specific DNA binding, cellular response to stress, and hemopoietic or lymphoid organ development.

Conclusions: These results suggest that the formation of different TCM syndromes in patients with HIV/ AIDS were founded on biological transcriptomics, which reveal mechanisms of the formation of these syndromes in HIV/AIDS. Differentially expressed mRNAs in two TCM syndrome groups tended to normalize after TCM intervention, which indicates that TCM might remit symptoms by changing genetic expression.
\end{abstract}

Keywords: differentially expressed genes, AIDS, HIV, TCM syndromes, qi-yin deficiency syndrome, dampness-heat retention syndrome

\footnotetext{
${ }^{1}$ Department of Clinical Foundation of TCM, Henan University of TCM, Zhengzhou, China.

${ }^{2}$ Department of Molecular Biology, Henan University of TCM, Zhengzhou, China.

${ }^{3}$ Department of Infection Epidemiology, The First Affiliated Hospital of Henan, University of TCM, Zhengzhou, China.

${ }^{4}$ Andrology of Henan, Chinese Medicine Hospital, Zhengzhou, China.

${ }^{5}$ Department of Diagnostics, Traditional Chinese Medicine, Henan University of TCM, Zhengzhou, China.

${ }^{6}$ College of Life Science, Tsinghua University, Beijing, China.

${ }^{7}$ AIDS Institute of Henan University of TCM, Henan University of TCM, Zhengzhou, China.

${ }^{8}$ Department of Internal Medicine of TCM, People's Hospital of Zhongmou County, Zhongmou, China.

*These authors contributed equally to this work.
}

(C) Sa Liu et al., 2016; Published by Mary Ann Liebert, Inc. This Open Access article is distributed under the terms of the Creative Commons Attribution Noncommercial License (http://creativecommons.org/licenses/by-nc/4.0/) which permits any noncommercial use, distribution, and reproduction in any medium, provided the original author(s) and the source are credited. 


\section{Introduction}

$\mathbf{P}$ ATHOGENESIS OF AIDS PARTLY depends on the ability of HIV to avoid host immunity; its ability to replicate in target cells, such as $\mathrm{CD} 4^{+} \mathrm{T}$ cells; and induction of apoptosis of immune cells. ${ }^{1}$ Although highly active anti-retroviral therapy can control viral load and incompletely restore immunity, it is associated with clinical drug resistance and side effects. ${ }^{2,3}$ Alternative and complementary therapies have been positively verified. ${ }^{4-6}$ Studies have shown that Traditional Chinese Medicine (TCM) has had some effects alone or when integrated with modern medicine in terms of reestablishing the immune system, reducing side effects, and personalized treatment. ${ }^{7-9}$ TCM can be used as an alternative and complementary therapy for AIDS. ${ }^{10}$ A precondition for effective clinical treatment with TCM has been the diagnosis of TCM syndromes in patients. Research on the molecular biological basis of TCM syndromes will provide a reference for diagnosis and evaluation of curative effect. ${ }^{11,12}$

The study of TCM syndromes in terms of transcriptomics is conducive to research on the molecular mechanisms of TCM syndromes and personalized treatment. ${ }^{13-16}$ Transcriptomics explores genetic transcription and regulation in cells at the overall level of RNA expression and variability. ${ }^{17,18}$ The interactions of differentially expressed genes might present different symptoms in patients, which corresponds to a characteristic of TCM: that is, TCM syndromes manifest timeliness and spatial awareness of a disease at a certain stage of development.

At present, some investigators have studied TCM syndromes in terms of transcriptomics. ${ }^{19,20}$ Transcriptomics in patients with HIV/AIDS has also been studied. ${ }^{21,22}$ However, gene expression profiles in HIV/AIDS with TCM syndromes has thus far not been explored. In addition, epidemiologic results have shown that the qi-yin deficiency syndrome $^{23-25}$ and dampness-heat retention ${ }^{26,27}$ were the most common TCM syndromes in patients with HIV/AIDS in China.. Therefore, the present study selected patients with these two TCM syndromes with the objective of studying expression profiles and exploring the inherent foundation of HIV/AIDS in TCM patients at the molecular level.

\section{Materials and Methods}

\section{General information}

Forty-nine volunteers were included in this study. Among them, 29 patients with HIV/AIDS were from the Henan province of China: 12 with qi-yin deficiency syndrome and 17 with dampness-heat retention. Twenty healthy persons from the same region and same ethnic group were included as a control group to ensure that the age, sex, eating habits, and lifestyle of the control group were similar to those of the observation group. Baseline demographic characteristics, such as age and sex, did not significantly differ between groups (Tables 1 and 2).

Table 1. Sex Distribution Between Groups

\begin{tabular}{lccc}
\hline Group & Men & Women & Total \\
\hline Case group $(n)$ & 17 & 12 & 29 \\
Control group $(n)$ & 10 & 10 & 20
\end{tabular}

Chi-square $=0.356 ; p=0.551$.
Table 2. Age Distribution Between Groups

\begin{tabular}{lcc}
\hline Group & Participants (n) & Mean age $(y r)$ \\
\hline Case group & 29 & $47.95 \pm 6.51$ \\
Control group & 20 & $47.25 \pm 8.13$ \\
\hline
\end{tabular}

Means are expressed with standard deviation. $t=0.382 ; p=0.703$.

The study was approved by the "Prevention and Treatment of Serious Infectious Diseases Such as AIDS and Viral Hepatitis Prevention" project management office of China. Each participant provided informed consent.

During the study, $5 \mathrm{~mL}$ of fasting anticoagulated blood was drawn from all participants in the morning; of this sample, $2 \mathrm{ml}$ was used for transcriptomic research, and the other $3 \mathrm{~mL}$ was used for viral load and immune indices detection. This latter analysis provided a reference for basic conditions of the disease in participants included for transcriptomics research.

\section{Inclusion criteria}

Patients with HIV/AIDS included in the present study were aged 18-60 years and met the diagnostic criteria of AIDS as described in the Diagnostic Guide of AIDS recommended by the Ministry of Health, China, in 2008.

\section{Criteria for TCM syndrome differentiation}

TCM syndromes were differentiated in two steps. First, two professors made the initial diagnosis. Second, commonly used diagnostic scales for TCM syndromes in HIV/AIDS were used as diagnostic criteria. A TCM syndrome was diagnosed when the total points were greater than or equal to 20 . The diagnostic scales were chosen according to the Science and Technology Prize of the China Association of TCM in 2012 (Epidemiologic Study and Diagnostic Scales of TCM Syndrome with HIV/ AIDS) and the National Natural Science Foundation of China (Distribution Rule of TCM Syndromes in HIV/AIDS and Building and Verification of Syndrome Criteria, no. 90409004). These were considered for their diagnostic scales for qi-yin deficiency syndrome and dampness-heat retention syndrome as the diagnostic criteria ${ }^{28}$ (Supplementary Tables S1 and S2; supplementary materials are available online at http://www .liebertpub.com/acm).

\section{Exclusion criteria}

The following were excluded from the study: (1) patients with AIDS in the middle or advanced stage of disease, with severe opportunistic infections; (2) patients with obnubilation, dementia, or other psychiatric/psychological disorders; (3) patients with severe organ disease or immunodeficiency disease that was induced by non-AIDS infections; and (4) patients who failed to provide informed consent for whatever reason.

\section{Medicines and methods for intervention}

Patients with HIV/AIDS who had corresponding TCM syndromes received an intervention with TCM granules (produced by Shenzhen San-Jiu Modern TCM Co., Ltd., in December 2010). The qi-yin deficiency group was treated with Shengmai decoction, ${ }^{29}$ which consisted of $5 \mathrm{~g}$ of Renshen (Panax ginseng), $15 \mathrm{~g}$ of Maidong (Ophiopogon japonicus), and $10 \mathrm{~g}$ of Wuweizi (Schisandra chinensis). The dampness- 


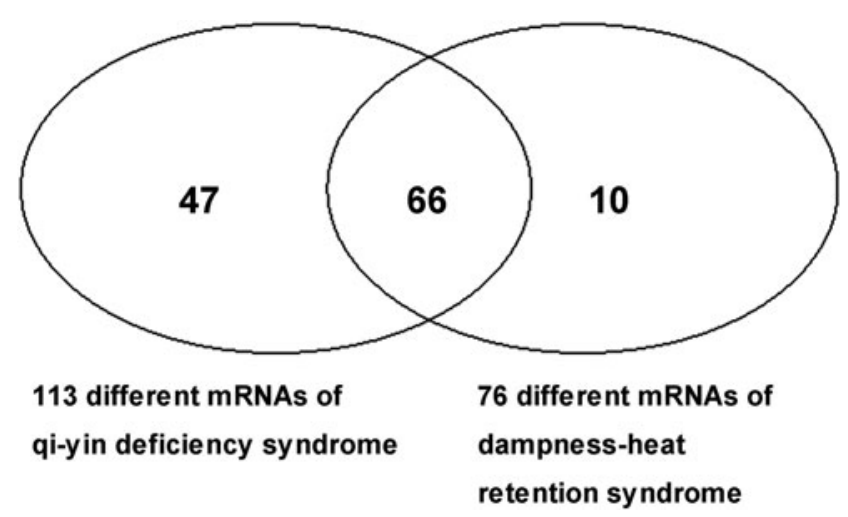

FIG. 1. Different messenger RNAs (mRNAs) of the two syndromes (qi-yin deficiency and dampness-heat retention).

heat retention group received Sanren decoction, ${ }^{30}$ consisting $15 \mathrm{~g}$ of Xingren (Amygdalus communis vas), $20 \mathrm{~g}$ of Yiyiren (Semen coicis), $10 \mathrm{~g}$ of Baikou (cardamom), $12 \mathrm{~g}$ of Jiangbanxia (ginger processed Pinellia ternata [Thunb.] Breit.), $10 \mathrm{~g}$ of Huashi (talcum), $15 \mathrm{~g}$ of Baizhu (Atractylodes macrocephala Koidz), $15 \mathrm{~g}$ of Houpu (Mangnolia officinalis Rehd. et Wils), $6 \mathrm{~g}$ of Tongcao (Tetrapanax papyriferus), and $10 \mathrm{~g}$ of Danzhuye (Herba Lophatheri). Directions and dosage were provided to the patients and included one bag to be taken twice daily, with $200 \mathrm{~mL}$ of warm water added so that participants could drink the contents. The course of treatment lasted 3 months, repeated twice (two courses total). Blood samples were obtained before and after treatment.

\section{Expression profile of the AFFX Human Genome U133 Plus 2.0 chips}

Total RNA extraction reagent was applied to extract total RNA from fasting blood samples from the three groups. Appropriate RNA was detected by using a nucleic acid quantitative analyzer and agarose gel electrophoresis to visualize the bands. Expression profile of total RNA was tested by AFFX Human Genome U133 Plus 2.0 chips.

\section{Data analysis}

The differential signal points were analyzed and screened with the BRB-Array Tools 4.2 software program. With the GENE SET program, an expression-comparing tool that was included in the software, differential genes between groups were tested. BRB-ArrayTools, version 4.2, was used in cluster analysis on differentially expressed signals in the healthy and the disease groups. The information pathways of differentially expressed messenger RNAs (mRNAs) were analyzed online by using DAVID tools (http://david.abcc .ncifcrf.gov/), and the interactions between them were analyzed by using STRING (http://string.embl.de). SPSS software, version 21.0 (IBM Corp., Armonk, NY) was used for statistical analysis.

\section{Results}

\section{Differential mRNAs in two syndrome groups}

Differential signals were screened to determine their corresponding differential mRNAs according to the following criteria: (1) $p<0.001$; (2) false discovery rate, $p<0.05$; and (3) ratio of 0.5 or less and ratio greater than 2 . Results showed that of the 113 differentially expressed mRNAs were found in the qi-yin deficiency group compared with the healthy group: 41 were upregulated (Supplementary Table S3) and 72 were downregulated (Supplementary Table S4). In addition, 76 differentially expressed mRNAs, 14 upregulated (Supplementary Table S5) and 62 downregulated (Supplementary Table S6) in the dampness-heat retention group, compared with the healthy group. With the exception of the shared differentially expressed mRNAs, 47

Table 3. Immunologic Indices Before Treatment per Study Group

\begin{tabular}{|c|c|c|c|c|c|}
\hline Immunologic index & $\begin{array}{l}\text { Qi-yin deficiency } \\
\text { pattern group }\end{array}$ & $\begin{array}{c}\text { Dampness-heat retention } \\
\text { pattern group }\end{array}$ & Control group & $\mathrm{F}$ & $\mathrm{p}$-Value \\
\hline $\mathrm{CD}^{+}{ }^{+}$count $\left(\right.$cells $\left./ \mathrm{mm}^{3}\right)$ & $349 \pm 172^{\mathrm{a}}$ & $372 \pm 105^{\mathrm{a}}$ & $880 \pm 290$ & 5.364 & 0.002 \\
\hline $\mathrm{CD}^{+}$count $\left(\operatorname{cell} / \mathrm{mm}^{3}\right)$ & $641 \pm 199$ & $761 \pm 245^{\mathrm{a}}$ & $508 \pm 253$ & 3.866 & 0.013 \\
\hline $\mathrm{CD}^{+} \mathrm{CD} 28^{+} / \mathrm{CD}^{+}(\%)$ & $39.19 \pm 13.09$ & $34.09 \pm 8.04$ & $39.24 \pm 8.85$ & 1.498 & 0.222 \\
\hline $\mathrm{CD}^{+} \mathrm{CD}^{+} 8^{+} / \mathrm{CD}^{+}(\%)$ & $48.90 \pm 16.40^{\mathrm{a}}$ & $57.62 \pm 20.20^{\mathrm{a}}$ & $35.93 \pm 10.16$ & 7.234 & $<0.000$ \\
\hline $\mathrm{CD}^{+}{ }^{+} \mathrm{CD}_{4} 5^{+} \mathrm{RA} / \mathrm{CD}^{+}(\%)$ & $32.19 \pm 12.07$ & $26.91 \pm 14.52^{\mathrm{a}}$ & $38.55 \pm 12.02$ & 3.058 & 0.034 \\
\hline $\mathrm{CD}^{+} \mathrm{CD}^{+} 5^{+} \mathrm{RO} / \mathrm{CD}^{+}(\%)$ & $62.39 \pm 10.21$ & $70.37 \pm 15.36$ & $61.98 \pm 11.73$ & 1.860 & 0.144 \\
\hline $\mathrm{CD}^{+} \mathrm{CD}^{\circ} 5^{+} / \mathrm{CD}^{+}(\%)$ & $45.59 \pm 16.36$ & $46.05 \pm 16.35$ & $38.13 \pm 8.62$ & 1.643 & 0.187 \\
\hline $\mathrm{CD}^{+}{ }^{+} \mathrm{CD} 28^{+} / \mathrm{CD}^{+}(\%)$ & $71.25 \pm 16.08$ & $61.05 \pm 21.61^{\mathrm{b}}$ & $77.61 \pm 8.86$ & 15.09 & 0.003 \\
\hline $\mathrm{CD} 4^{+} \mathrm{CD} 25^{+} / \mathrm{CD}^{+}(\%)$ & $14.46 \pm 8.90$ & $8.71 \pm 3.74$ & $11.90 \pm 4.41$ & 2.463 & 0.069 \\
\hline $\mathrm{CD}^{-} \mathrm{CD}^{-} 6^{+} 56^{+} / \mathrm{Lym}(\%)$ & $16.84 \pm 10.72$ & $16.64 \pm 8.83$ & $22.56 \pm 11.19$ & 1.986 & 0.096 \\
\hline
\end{tabular}

Values expressed with a plus/minus sign are the mean \pm standard deviation. SPSS 21.0 statistical software program was used to analyze relevant immune indices in different TCM syndromes. One-way analysis of variance was applied to analyze and compare the intergroup differences. To compare the differences in immune indices between groups, the least-squares difference method was selected for equal variances; the Dunnett T3 test was used for unequal variances. The results showed that when compared with values in the control group, the absolute value of $\mathrm{CD} 4^{+} \mathrm{T}$ cells in both disease groups was reduced significantly, while the frequency of $\mathrm{CD} 8^{+} \mathrm{CD} 38^{+} \mathrm{T}$ cells increased significantly $(p<0.05-0.01)$. Further, compared with the control group, the qi-yin deficiency group had a significant decrease in absolute values of $\mathrm{CD}^{+}$and $\mathrm{CD} 8^{+} \mathrm{T}$ cells $(p<0.05-0.01)$, while the dampness-heat retention group had a significant increase in CD8 T cells and reduced frequency of $\mathrm{CD} 4^{+} \mathrm{CD} 45 \mathrm{RA}^{+}$and $\mathrm{CD} 4^{+} \mathrm{CD} 28^{+}$dual-positive $\mathrm{T}$ cells $(p<0.05-0.01)$. There were no significant difference seen between groups in $\mathrm{CD}^{+} \mathrm{CD} 28^{+}$and $\mathrm{CD} 4^{+} \mathrm{CD} 45 \mathrm{RO}^{+} \mathrm{T}$ cells, $\mathrm{CD} 4^{+} \mathrm{CD} 95^{+}$, and $\mathrm{CD} 4^{+} \mathrm{CD} 25^{+} \mathrm{T}$ cells or the $\mathrm{CD} 3^{-} \mathrm{CD} 16^{+} 56^{+} \mathrm{T}$ cells $(p>0.05)$.

${ }_{\mathrm{b}}^{\mathrm{a}} p<0.01$ compared with healthy controls.

${ }^{\mathrm{b}} p<0.05$ compared with healthy controls. 
Table 4. Predicted and Classified of Differential Genes in the Two Traditional Chinese Medicine Syndrome Groups

\begin{tabular}{lcccc}
\hline Number & Parametric p-value & t-value & Fold-change & Gene symbol \\
\hline 1 & 0.006712 & -2.946 & 0.64 & DDX11L2 \\
2 & 0.006805 & 2.94 & 1.53 & PNP \\
3 & 0.006365 & 2.968 & 1.61 & GPR18 \\
4 & 0.004938 & 3.072 & 2.42 & RPS26 \\
5 & 0.004692 & 3.093 & 2.26 & MS4A1 \\
6 & 0.003681 & 3.191 & 1.64 & BANK1 \\
7 & 0.002231 & 3.392 & 4.52 & XIST
\end{tabular}

Differentially expressed genes in either group were predicted and classified according to the significance level of $p<0.05$, fold change $\geq 1.5$. The accuracy of compound covariate predictor was 86\%; accuracy of diagonal linear discriminant analysis was $93 \%$; accuracy of three nearest neighbors was $79 \%$; accuracy of nearest centroid was $93 \%$, accuracy of the support vector machines was $93 \%$; and accuracy of the Bayesian compound covariate predictor was $96 \%$.

mRNAs were specific to the qi-yin deficiency group and 10 were specific to the dampness-heat retention group (Fig. 1).

\section{Prediction and classification of differentially expressed mRNAs}

To verify the specificity of differentially expressed mRNAs in both syndrome groups, all differentially expressed genes in each group were predicted and classified according to the significance level of $p<0.05$. In addition, fold-change of 1.5 or greater and seven genes, including RPS26, MS4A1, and XIST (Table 4), were screened. Dif- ferentially expressed mRNAs in both TCM syndrome groups could be distinguished, and the specific biological basis of the TCM syndromes could be verified.

\section{Functional annotation clustering of differentially expressed $m R N A s$}

The biological function of differentially expressed mRNAs in both TCM syndrome groups was analyzed by functional annotation clustering in DAVID tools. Some differentially expressed genes were correlated with apoptosis, response to material, immune response, chemotaxis,
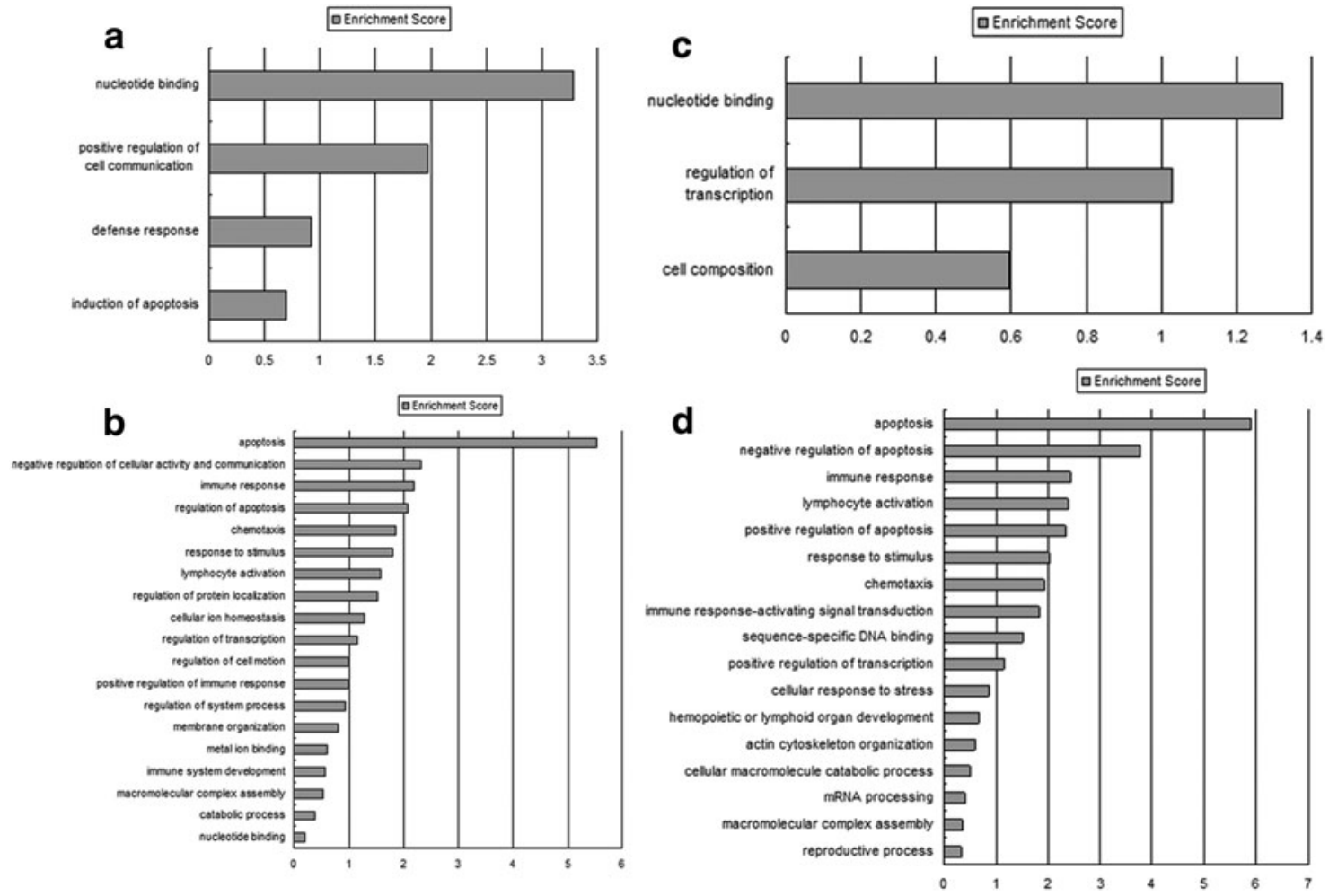

FIG. 2. Upregulated and downregulated mRNAs in both differential syndromes were analyzed by using DAVID tools. After the results of the functional annotation clustering were obtained, a bar chart was drawn with the enrichment score (yaxis) and function (x-axis). Differentially expressed genes that were relevant to the function with a greater enrichment score had a greater role in disease progression and syndrome formation in HIV. Functional annotation of upregulated and downregulated mRNAs in qi-yin deficiency syndrome was showed, respectively, in (a) and (b). Functional annotation of upregulated and downregulated mRNAs was showed, respectively, in (c) and (d). 
Table 5. Signaling Pathways of Different Messenger RnAs of the QI-Yin Deficiency Syndrome

\begin{tabular}{|c|c|c|c|c|c|}
\hline Category & Term & Count & $\%$ & p-Value & Gene symbol \\
\hline KEGG & hsa04062: Chemokine signaling pathway & 9 & 0.87 & $1.93 \mathrm{E}-04$ & CXCL1, GNAI3, PPBP, IL8, CXCR4, \\
\hline KEGG & $\begin{array}{l}\text { hsa04060: Cytokine-cytokine receptor } \\
\text { interaction }\end{array}$ & 9 & 0.87 & 0.001822 & $\begin{array}{l}\text { CXCL1, IL1R2, TNFSF10, PPBP, IL8, } \\
\text { CXCR4, CCR2, CX3CR1, IL1B }\end{array}$ \\
\hline KEGG & $\begin{array}{l}\text { hsa04621: NOD-like receptor signaling } \\
\text { pathway }\end{array}$ & 5 & 0.48 & 0.002054 & CXCL1, IL8, NFKBIA, IL1B, TNFAIP3 \\
\hline KEGG & hsa04210: Apoptosis & 4 & 0.38 & 0.040987 & CFLAR, TNFSF10, NFKBIA, IL1B \\
\hline KEGG & $\begin{array}{l}\text { hsa04620: Toll-like receptor signaling } \\
\text { pathway }\end{array}$ & 4 & 0.38 & 0.059209 & $F O S, I L 8, N F K B I A, I L 1 B$ \\
\hline KEGG & hsa04010: MAPK signaling pathway & 6 & 0.58 & 0.084914 & $\begin{array}{l}\text { FOS, IL1R2, DUSP1, RRAS2, } \\
\quad J U N D, I L 1 B\end{array}$ \\
\hline BioCarta & $\begin{array}{l}\text { h_nthiPathway: NFkB activation } \\
\text { by nontypeable Haemophilus } \\
\text { influenzae }\end{array}$ & 4 & 0.38 & 0.003331 & DUSP1, IL8, NFKBIA, IL1B \\
\hline BioCarta & $\begin{array}{l}\text { h_cd40Pathway: CD40L signaling } \\
\text { pathway }\end{array}$ & 3 & 0.29 & 0.013717 & DUSP1, NFKBIA, TNFAIP3 \\
\hline BioCarta & $\begin{array}{l}\text { h_tnfr2Pathway: TNFR2 signaling } \\
\text { pathway }\end{array}$ & 3 & 0.29 & 0.020021 & DUSP1, NFKBIA, TNFAIP3 \\
\hline BioCarta & $\begin{array}{l}\text { h_deathPathway: Induction of apoptosis } \\
\text { through DR3 and DR4/5 death } \\
\text { receptors }\end{array}$ & 3 & 0.29 & 0.057829 & CFLAR, TNFSF10, NFKBIA \\
\hline BioCarta & $\begin{array}{l}\text { h_il2rbPathway: IL-2 receptor } \beta \text { chain } \\
\text { in T cell activation }\end{array}$ & 3 & 0.29 & 0.068567 & FOS, CFLAR, SOCS3 \\
\hline
\end{tabular}

Signal pathways of differential genes in both syndromes were analyzed with DAVID tools (http://david. abcc.ncifcrf.gov/). Both syndromes had the same and specific signals. Both the differentially expressed genes and the statistical $p$-values of both Traditional Chinese Medicine syndromes were different in terms of the common signaling pathways.

KEGG, Kyoto Encyclopedia of Genes and Genomes; NOD, nucleotide oligomerization domain; MAPK, mitogen-activated protein kinase; NFאB, nuclear factor $\kappa \mathrm{B}$; TNFR2, tumor necrosis factor receptor 2; DR, death receptor; IL-2, interleukin-2.

Table 6. Signaling Pathways of Different Messenger RnAs of the Dampness-Heat Retention Syndrome

\begin{tabular}{|c|c|c|c|c|c|}
\hline Category & Term & Count & $\%$ & p-Value & Gene symbol \\
\hline KEGG & $\begin{array}{l}\text { hsa04621: NOD-like receptor } \\
\text { signaling pathway }\end{array}$ & 6 & 0.84 & 4.18E-05 & $\begin{array}{l}\text { CXCL1, IL8, NFKBIA, ILIB, RIPK2, } \\
\text { TNFAIP3 }\end{array}$ \\
\hline KEGG & $\begin{array}{l}\text { hsa04620: Toll-like receptor } \\
\text { signaling pathway }\end{array}$ & 5 & 0.70 & 0.003855 & FOS, ILS, NFKBIA, ILIB, CCL4 \\
\hline KEGG & $\begin{array}{l}\text { hsa04062: Chemokine signaling } \\
\text { pathway }\end{array}$ & 6 & 0.84 & 0.006544 & $\begin{array}{l}\text { CXCL1, IL8, CXCR4, CX3CR1, NFKBIA, } \\
\text { CCL4 }\end{array}$ \\
\hline KEGG & $\begin{array}{l}\text { hsa04060: Cytokine-cytokine } \\
\text { receptor interaction }\end{array}$ & 6 & 0.84 & 0.025379 & $\begin{array}{l}C X C L 1, I L 8, C X C R 4, C X 3 C R 1, I L 1 B, \\
\text { CCL4 }\end{array}$ \\
\hline KEGG & $\begin{array}{l}\text { hsa04623: Cytosolic DNA-sensing } \\
\text { pathway }\end{array}$ & 3 & 0.42 & 0.048982 & NFKBIA, ILIB, CCLA \\
\hline KEGG & $\begin{array}{l}\text { hsa05120: Epithelial cell signaling } \\
\text { in Helicobacter pylori infection }\end{array}$ & 3 & 0.42 & 0.071348 & CXCL1, IL8, NFKBIA \\
\hline BioCarta & $\begin{array}{l}\text { h_nthiPathway: NFKB activation } \\
\text { by nontypeable } H \text { influenzae }\end{array}$ & 4 & 0.56 & 0.00239 & DUSP1, IL8, NFKBIA, IL1B \\
\hline BioCarta & $\begin{array}{l}\text { h_Ccr5Pathway: Pertussis } \\
\text { toxin-insensitive CCR5 signaling } \\
\text { in macrophage }\end{array}$ & 3 & 0.42 & 0.011031 & FOS, CXCR4, CCLA \\
\hline BioCarta & $\begin{array}{l}\text { h_cd40Pathway: CD } 40 \mathrm{~L} \\
\text { signaling pathway }\end{array}$ & 3 & 0.42 & 0.011031 & DUSP1, NFKBIA, TNFAIP3 \\
\hline BioCarta & $\begin{array}{l}\text { h_tnfr2Pathway: TNFR2 } \\
\text { signaling pathway }\end{array}$ & 3 & 0.42 & 0.016146 & DUSP1, NFKBIA, TNFAIP3 \\
\hline BioCarta & $\begin{array}{l}\text { h_il2rbPathway: IL-2 receptor } \beta \\
\text { chain in T cell activation }\end{array}$ & 3 & 0.42 & 0.056103 & FOS, CFLAR, SOCS3 \\
\hline
\end{tabular}

Signal pathways of differential genes in both syndromes were analyzed with DAVID tools (http://david. abcc.ncifcrf.gov/). Both syndromes had the same and specific signals. Both the differentially expressed genes and the statistical $p$-values of both Traditional Chinese Medicine syndromes were different in terms of the common signaling pathways. 
FIG. 3. Pathways of differentially expressed mRNAs in qi-yin deficiency syndrome (a) and dampnessheat retention syndrome (b) were obtained through DAVID tools. Bar charts were constructed, with the $p$-value displayed on the $\mathrm{X}$-axis and the specific pathway on the y-axis. Pathwayrelated differential genes with lower $p$-values had a greater role in disease progression and syndrome formation seen in HIV/AIDS.

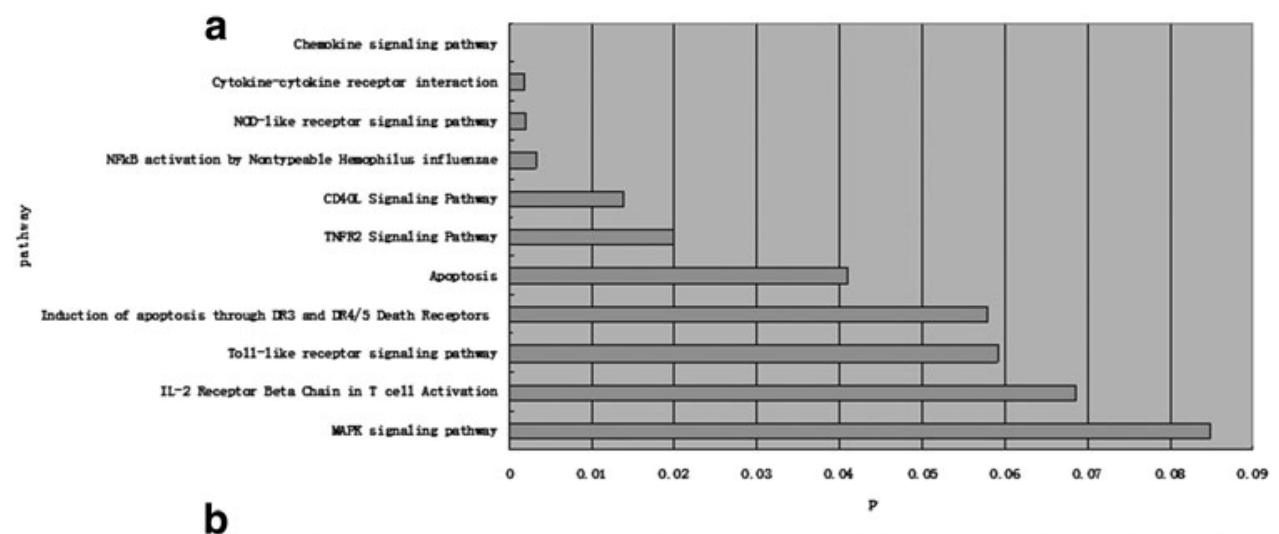

b

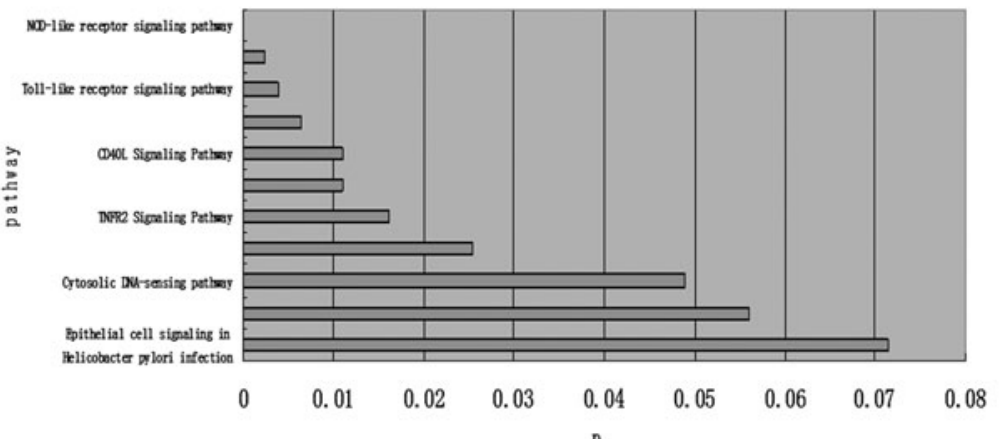

and lymphocyte activation (Supplementary Tables S7-S10). However, differential syndromes had different enrichment scores in the same annotation cluster.

Differentially expressed genes specific to both syndromes had differential functions. Functions specific to upregulated mRNAs in qi-yin deficiency syndrome were related to positive regulation of cell communication, induction of apoptosis, and other features (Fig. 2a). Downregulated mRNAs were obviously related to negative regulation of cellular activity and communication, regulation of protein localization, cellular ion homeostasis, and other features (Fig. 2b). Functions specific to the dampness-heat retention syndrome included the following: Upregulated mRNAs were correlated with regulation of transcription and cell composition (Fig. 2c), and downregulated mRNAs were involved in negative regulation of apoptosis, mRNA processing, sequence-specific DNA binding, cellular response to stress, hemopoietic or lymphoid organ development, and other features (Fig. 2d).
FIG. 4. With the BRBArray Tools version 4.2 software, differentially expressed signals of the healthy control group and the syndrome groups were analyzed. Upregulated genes are shown in red and downregulated genes are displayed in green. From the image, it can be appreciated that the genetic expression in the healthy group and the disease groups was clearly different according to the color map. Partial differences in genetic expression for both syndrome groups could also be manifested in the cluster analysis image. Color images available online at www .liebertpub.com/acm

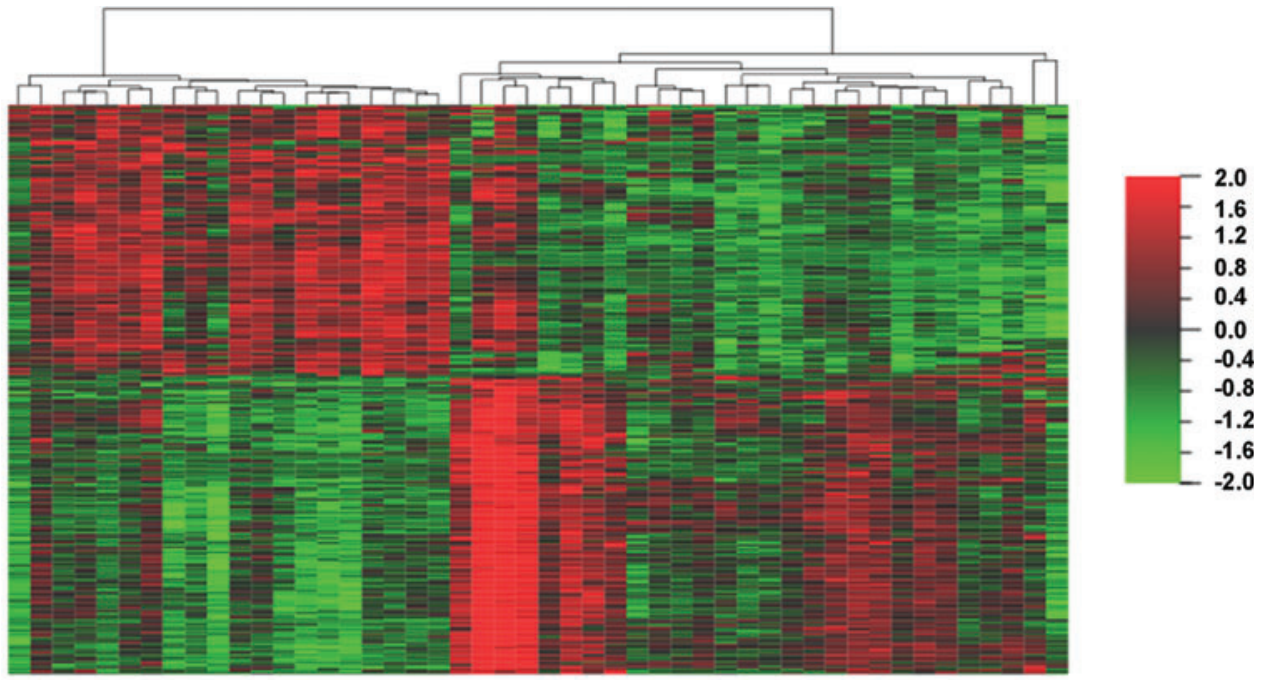

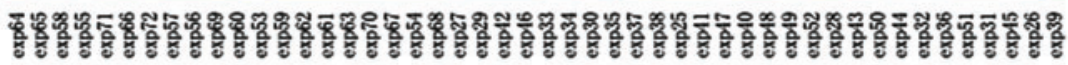

healthy control group disease group 


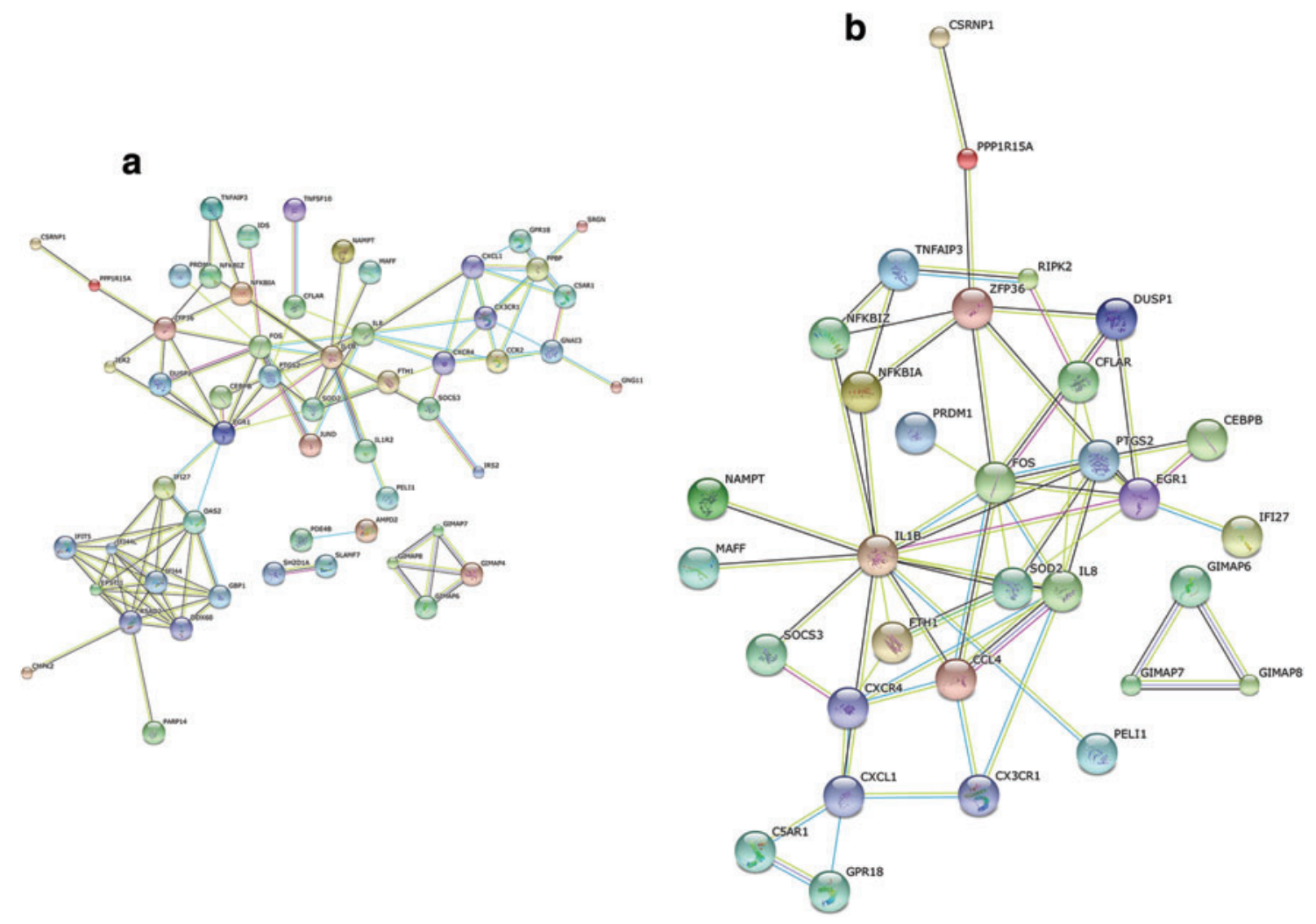

FIG. 5. Differential mRNAs of both syndromes were loaded into STRING. Required confidence (score) was 0.70 , and interactors shown were no greater than 5. Differentially expressed mRNAs, which were closely related to each other, 56 mRNAs were found in the qi-yin deficiency syndrome (a), while $32 \mathrm{mRNAs}$ were found in the dampness-heat retention syndrome (b). Lines in the diagram represent the relations between gene functions, whose intimacy level was represented by the length of the line. Color images available online at www.liebertpub.com/acm

\section{Pathways of differentially expressed mRNAs}

To further grasp the mechanism of differentially expressed genes in TCM syndromes, DAVID tools were applied to analyze the pathways of these genes. Both syndromes had common pathways and specific pathways (Tables 5 and 6; Fig. $3 a$ and $3 b)$.

\section{Cluster analysis}

Differentially expressed signals of the healthy group and both of the syndrome groups were analyzed with BRBArray Tools, version 4.2. According to the cluster analysis of the genetic expression levels, both the healthy group and the disease groups can be distinguished in color, which indicated that the healthy group and the disease groups had different genetic expression profiles. Both syndrome groups could also be partly differentiated, which showed that there were both similar the specific differentially expressed mRNAs seen between different syndromes (Fig. 4).

\section{Interaction between differentially expressed genes}

Differentially expressed mRNAs of both syndromes were input into STRING in order to intuitively study the correlation between them. The required confidence (score) was 0.70 , and the interactors shown yielded a value that was no greater than 5. Differentially expressed mRNAs, which were closely related to each other, were found in the qi-yin deficiency syndrome group, making up a relationship chart with 56 nodal points and a side-length of 112 (Fig. 5a). According to the same standards, 32 differentially expressed mRNAs, which were closely related to each other, were found in the dampness-heat retention syndrome group, forming a relationship chart with 32 nodal points and a sidelength of 54 (Fig. 5b).

Table 7. Scores of the Traditional Chinese Medicine Syndrome Before and After Treatment

\begin{tabular}{lccrrr}
\hline Group & Participants (n) & $\begin{array}{c}\text { Scores before } \\
\text { TCM treatment }\end{array}$ & $\begin{array}{c}\text { Scores after } \\
\text { TCM treatment }\end{array}$ & $\mathrm{t}$ & $\mathrm{p}$-Value \\
\hline Qi-yin deficiency syndrome & 12 & $32.42 \pm 10.30$ & $13.18 \pm 2.56$ & 4.859 & 0.0001 \\
Dampness-heat retention syndrome & 17 & $29.47 \pm 6.51$ & $10.46 \pm 6.54$ & 7.909 & 0.0001 \\
\hline
\end{tabular}

Values expressed with a plus/minus sign are means \pm standard deviation.

TCM, Traditional Chinese Medicine. 
Table 8. Immune Indices Before And After TCM Treatment

\begin{tabular}{|c|c|c|c|c|}
\hline \multirow[b]{2}{*}{ Immune index } & \multicolumn{2}{|c|}{ Qi-yin deficiency syndrome } & \multicolumn{2}{|c|}{ Dampness-heat retention syndrome } \\
\hline & Before TCM treatment & After TCM treatment & Before TCM treatment & After TCM treatment \\
\hline $\mathrm{CD}^{+}$count $\left(\right.$cells $\left./ \mathrm{mm}^{3}\right)$ & $349 \pm 172$ & $389 \pm 264$ & $372 \pm 105$ & $386 \pm 152$ \\
\hline $\mathrm{CD}^{+}$count $\left(\right.$cells $\left./ \mathrm{mm}^{3}\right)$ & $641 \pm 199$ & $985 \pm 477^{\mathrm{a}}$ & $761 \pm 245$ & $896 \pm 274$ \\
\hline $\mathrm{CD}^{+} \mathrm{CD} 28^{+} / \mathrm{CD}^{+}(\%)$ & $39.19 \pm 13.09$ & $62.17 \pm 16.22^{\mathrm{b}}$ & $34.09 \pm 8.04$ & $57.85 \pm 12.98^{\mathrm{b}}$ \\
\hline $\mathrm{CD}^{+} \mathrm{CD}^{+} 8^{+} / \mathrm{CD}^{+}(\%)$ & $48.90 \pm 16.40$ & $38.29 \pm 14.07$ & $57.62 \pm 20.20$ & $40.88 \pm 13.36^{\mathrm{b}}$ \\
\hline $\mathrm{CD}^{+}{ }^{+} \mathrm{CD} 45^{+} \mathrm{RA} / \mathrm{CD}^{+}(\%)$ & $32.19 \pm 12.07$ & $31.87 \pm 9.73$ & $26.91 \pm 14.52$ & $22.68 \pm 12.32$ \\
\hline $\mathrm{CD}^{+}{ }^{+} \mathrm{CD} 45^{+} \mathrm{RO} / \mathrm{CD}^{+}(\%)$ & $62.39 \pm 10.21$ & $57.10 \pm 16.03$ & $70.37 \pm 15.36$ & $59.78 \pm 19.51$ \\
\hline $\mathrm{CD}^{+} \mathrm{CD}^{+} 5^{+} / \mathrm{CD}^{+}(\%)$ & $45.59 \pm 16.36$ & $61.25 \pm 20.25^{\mathrm{a}}$ & $46.05 \pm 16.35$ & $60.59 \pm 18.56^{\mathrm{a}}$ \\
\hline $\mathrm{CD}^{+} \mathrm{CD}^{2} 8^{+} / \mathrm{CD}^{+}(\%)$ & $71.25 \pm 16.08$ & $53.79 \pm 23.90$ & $61.05 \pm 21.61$ & $64.36 \pm 22.07$ \\
\hline $\mathrm{CD}^{+} \mathrm{CD}^{2} 5^{+} / \mathrm{CD} 4^{+}(\%)$ & $14.46 \pm 8.90$ & $17.57 \pm 11.38$ & $8.71 \pm 3.74$ & $11.06 \pm 4.68$ \\
\hline $\mathrm{CD}^{-} \mathrm{CD} 16^{+} 56^{+} / \mathrm{Lym}(\%)$ & $16.84 \pm 10.72$ & $17.84 \pm 10.85$ & $16.64 \pm 8.83$ & $17.71 \pm 8.02$ \\
\hline
\end{tabular}

The differences in the immune indices before and after TCM treatment were analyzed and compared. After receipt of medicine, $\mathrm{CD} 8^{+} \mathrm{CD} 28^{+} \mathrm{T}$ cells and $\mathrm{CD} 4^{+} \mathrm{CD} 95^{+} \mathrm{T}$ cells increased significantly in both syndrome groups $(p<0.05-0.01)$. The absolute value of CD ${ }^{+}$ $\mathrm{T}$ cells increased significantly in the qi-yin deficiency syndrome group $(p<0.05)$ and the $\mathrm{CD} 8^{+} \mathrm{CD} 38^{+} \mathrm{T}$ cells were reduced sharply in the dampness-heat retention syndrome group $(p<0.01)$. There were no significant changes in other indices $(p>0.05)$.

${ }_{p}^{a} p<0.05$ for comparison of before and after TCM treatment.

${ }^{b} p<0.01$ for comparison of before and after TCM treatment.

\section{Changes in $m R N A$ expression in both syndromes after TCM treatment}

To further grasp the roles of differential genes in TCM treatment, two TCM interventions were applied to treat patients with HIV/AIDS and the corresponding syndromes. Clinical symptoms total scores were reduced after treatment in two pattern groups $(p<0.05$; Table 7$)$, and immunologic indexes changed after treatment $(p<0.05$; Table 8$)$. These results can objectively prove the reliability of the TCM curative effect.

Comparison of genetic expression in the healthy control group before and after treatment showed that 18 mRNAs in patients with HIV/AIDS normalized; this involved 15 pathways that were mainly related to cellular apoptosis and inflammation (Tables 9 and 10). Moreover, 35 mRNAs in the qi-yin deficiency group normalized and involved eight pathways (Tables 11 and 12). In addition, 25 mRNAs in the dampness-heat retention syndrome that involved 17 pathways normalized (Tables 13 and 14). Through the prognosis of genes, the material basis of transcriptomic analysis in the qi-yin deficiency syndrome and the dampness-heat retention syndrome could be initially verified.

After the intervention, the normalized genes in both syndrome groups were obtained and separately applied into hierarchical clustering analysis with the genes in the patient groups and the healthy control group. Results showed that compared with the expression before treatment, the expression of genes in both syndrome groups after treatment was close to that shown for the healthy control group. In addition, even some genes in the qi-yin deficiency syndrome were misclassified into the healthy control group after treatment (Fig. 6a and 6b).

Table 9. Eighteen Genetic Expressions Close to the Healthy Control Group IN HIV/AIDS PATIENTS, NoRMALIZED

\begin{tabular}{llccc}
\hline Probe set ID & Gene symbol & After vs. healthy & Before vs. healthy & After vs. before \\
\hline 230333_at & - & 0.6658 & 0.314186 & 2.0196 \\
236495_at & - & 0.6002 & 0.260687 & 2.2371 \\
243296_at & NAMPT & 0.5341 & 0.237821 & 2.1741 \\
243509_at & - & 0.5337 & 0.236277 & 2.1398 \\
205681_at & BCL2A1 & 0.4042 & 0.22675 & 1.7128 \\
201502_s_at & NFKBIA & 0.3995 & 0.159954 & 2.3892 \\
223217_s_at & NFKBIZ & 0.3825 & 0.180093 & 1.9869 \\
223218_s_at & NFKBIZ & 0.3218 & 0.194865 & 1.5828 \\
204748_at & PTGS2 & 0.3175 & 0.113928 & 0.022876 \\
213524_s_at & GOS2 & 0.1948 & 0.035374 & 7.1192 \\
202859_x_at & IL8 & 0.1694 & 0.435402 & 1.6883 \\
212130_x_at & EIF1 & 0.6739 & 0.446181 & 1.5164 \\
212227_x_at & EIF1 & 0.6885 & 0.493156 & 1.5024 \\
230529_at & HECA & 0.7672 & 0.462924 & 1.6302 \\
201531_at & ZFP36 & 0.7496 & 0.468069 & 1.6562 \\
239757_at & ZFAND6 & 0.7987 & 0.385722 & 1.8355 \\
204285_s_at & PMAIP1 & 0.7278 & 0.64449 & 1.8954 \\
212341_at & YIPF6 & 1.245 & & \\
\hline
\end{tabular}


Table 10. Pathway of Genetic Expressions Close to the Healthy Control Group in HIV/AIDS Patients, Normalized

\begin{tabular}{|c|c|c|c|c|}
\hline Pathway & Count & $\mathrm{p}$-Value & q-Value & Gene symbol \\
\hline Epithelial cell signaling in $H$ pylori infection & 2 & $1.50 \mathrm{E}-04$ & $9.09 \mathrm{E}-05$ & NFKBIA, IL8 \\
\hline Small-cell lung cancer & 2 & $2.27 \mathrm{E}-04$ & $9.09 \mathrm{E}-05$ & NFKBIA, PTGS2 \\
\hline Toll-like receptor signaling pathway & 2 & $3.19 \mathrm{E}-04$ & $1.06 \mathrm{E}-04$ & NFKBIA, IL8 \\
\hline Nicotinate and nicotinamide metabolism & 1 & 0.00627 & $2.70 \mathrm{E}-04$ & $N A M P T$ \\
\hline Bladder cancer & 1 & 0.010949 & 4.13E-04 & IL8 \\
\hline Arachidonic acid metabolism & 1 & 0.014833 & $5.20 \mathrm{E}-04$ & PTGS2 \\
\hline Adipocytokine signaling pathway & 1 & 0.017414 & $6.00 \mathrm{E}-04$ & NFKBIA \\
\hline p53 signaling pathway & 1 & 0.017929 & $6.03 \mathrm{E}-04$ & PMAIP1 \\
\hline B cell receptor signaling pathway & 1 & 0.019474 & $6.25 \mathrm{E}-04$ & NFKBIA \\
\hline Chronic myeloid leukemia & 1 & 0.019474 & $6.25 \mathrm{E}-04$ & NFKBIA \\
\hline VEGF signaling pathway & 1 & 0.019732 & $6.25 \mathrm{E}-04$ & PTGS2 \\
\hline Prostate cancer & 1 & 0.022814 & $6.89 \mathrm{E}-04$ & NFKBIA \\
\hline Apoptosis & 1 & 0.023071 & $6.89 \mathrm{E}-04$ & NFKBIA \\
\hline T cell receptor signaling pathway & 1 & 0.028188 & $7.27 \mathrm{E}-04$ & NFKBIA \\
\hline Cytokine-cytokine receptor interaction & 1 & 0.066526 & 0.001401 & IL8 \\
\hline
\end{tabular}

HIV/AIDS patients with both syndromes were considered as disease groups. The genetic expression profiles seen before and after drug intervention were compared. After intervention, the degree of expression of 18 differentially expressed genes progressed toward the healthy control group. Through analysis of signaling pathways, 15 pathways, such as cellular apoptosis and inflammation, were related to normalized genes. When $p<0.05$, there were 14 signaling pathways related to normalized genes.

VEGF, vascular endothelial growth factor.

Table 11. Thirty-Five Genetic Expressions Close to the Healthy Control Group IN THE QI-YIN DEFICIENCY GROUP

\begin{tabular}{|c|c|c|c|c|}
\hline Probe set ID & Gene symbol & After vs. healthy & Before vs. healthy & After vs. before \\
\hline 206765_at & KCNJ2 & 2.1083 & 2.994986 & 0.6208 \\
\hline 242625_at & $R S A D 2$ & 2.0502 & 4.478901 & 0.6183 \\
\hline 202270_at & $G B P 1$ & 1.574 & 2.77847 & 0.6169 \\
\hline 214329_x_at & TNFSF 10 & 1.5426 & 2.806688 & 0.6211 \\
\hline 228071_at & GIMAP7 & 1.5416 & 2.744963 & 0.566 \\
\hline 203761_at & $S L A$ & 1.2939 & 2.065447 & 0.6 \\
\hline 219243_at & GIMAP4 & 1.362 & 2.025492 & 0.6612 \\
\hline 209112_at & $C D K N 1 B$ & 0.7699 & 1.533911 & 0.49 \\
\hline 203455_s_at & SAT1 & 0.6496 & 0.414196 & 1.7452 \\
\hline $210592 \mathrm{~s}$ at & SAT1 & 0.6478 & 0.395959 & 1.7694 \\
\hline 236495_at & - & 0.6052 & 0.204204 & 2.1291 \\
\hline 201041_s_at & DUSP1 & 0.5901 & 0.178339 & 3.3486 \\
\hline 225557_at & CSRNP1 & 0.5773 & 0.399585 & 1.5136 \\
\hline 211998_at & $H 3 F 3 B$ & 0.5082 & 0.308164 & 1.8047 \\
\hline 214211_at & FTH1 & 0.4948 & 0.303608 & 1.562 \\
\hline 243296_at & $N A M P T$ & 0.4463 & 0.22214 & 2.0051 \\
\hline 243509_at & - & 0.4416 & 0.202034 & 2.2336 \\
\hline 205681_at & BCL2A1 & 0.3947 & 0.217273 & 1.9054 \\
\hline 201502_s_at & $N F K B I A$ & 0.3884 & 0.160713 & 2.451 \\
\hline 204748_at & PTGS2 & 0.3686 & 0.102077 & 3.5925 \\
\hline 204470_at & CXCL1 & 0.3623 & 0.208837 & 1.5576 \\
\hline 223217_s_at & NFKBIZ & 0.3587 & 0.169925 & 2.1394 \\
\hline 223218_s_at & $N F K B I Z$ & 0.3464 & 0.189468 & 2.0542 \\
\hline 205114_s_at & $C C L 3$ & 0.2607 & 0.162641 & 1.9618 \\
\hline 213524_s_at & GOS2 & 0.224 & 0.017729 & 12.0734 \\
\hline 202859_x_at & IL8 & 0.166 & 0.030291 & 5.7922 \\
\hline 201473_at & $J U N B$ & 0.8657 & 0.489024 & 1.7308 \\
\hline 220046_s_at & CCNL1 & 0.7697 & 0.502441 & 1.7463 \\
\hline 230529_at & $H E C A$ & 0.7359 & 0.446418 & 1.6649 \\
\hline 202081_at & $I E R 2$ & 0.6942 & 0.469971 & 1.5566 \\
\hline 201531_at & ZFР36 & 0.7612 & 0.411515 & 1.8872 \\
\hline 239757_at & ZFAND6 & 0.7993 & 0.42851 & 1.9121 \\
\hline 204285_s_at & PMAIP1 & 0.7395 & 0.404904 & 1.9356 \\
\hline 1555411_a_at & CCNL1 & 0.7678 & 0.486916 & 1.5989 \\
\hline 200844_s_at & PRDX6 & 1.5956 & 0.638738 & 1.9763 \\
\hline
\end{tabular}


Table 12. Pathway of Genetic Expression Close to the Healthy Control Group IN THE QI-YIN DeFICIENCY GROUP

\begin{tabular}{lcccl}
\hline Pathway & Count & p-Value & q-Value & Gene symbol \\
\hline Epithelial cell signaling in H pylori infection & 3 & $1.64 \mathrm{E}-05$ & $4.11 \mathrm{E}-06$ & NFKBIA, CXCL1, IL8 \\
Small-cell lung cancer & 3 & $3.05 \mathrm{E}-05$ & $6.03 \mathrm{E}-06$ & CDKN1B, NFKBIA, PTGS2 \\
Cytokine-cytokine receptor interaction & 4 & $3.32 \mathrm{E}-05$ & $6.03 \mathrm{E}-06$ & TNFSF10, CXCL1, CCL3, IL8 \\
Toll-like receptor signaling pathway & 3 & $5.07 \mathrm{E}-05$ & $6.76 \mathrm{E}-06$ & NFKBIA, CCL3, IL8 \\
Systemic lupus erythematosus & 3 & $1.41 \mathrm{E}-04$ & $1.28 \mathrm{E}-05$ & H3F3B, LOC644914, H3F3A \\
Chronic myeloid leukemia & 2 & 0.001271 & $7.48 \mathrm{E}-05$ & CDKN1B, NFKBIA \\
Prostate cancer & 2 & 0.001743 & $9.90 \mathrm{E}-05$ & CDKN1B, NFKBIA \\
Apoptosis & 2 & 0.001783 & $9.90 \mathrm{E}-05$ & TNFSF10, NFKBIA \\
\hline
\end{tabular}

Gene expression in HIV/AIDS patients with the qi-yin deficiency syndrome before and after intervention was compared. After intervention, 35 differentially expressed genes that involved eight signaling pathways progressed toward the healthy control group $(p<0.05)$. Compared with the results seen in the dampness-heat retention group, both syndromes had both similar and different pathways, and normalized genes that were present in both syndromes were not all the same.

\section{Discussion}

TCM syndrome is an overall manifestation of a disease at a certain stage of development. It may have some correlation with differentially expressed mRNAs in the body. Transcriptomics applies chip technology to explore relevant genetic expression profiles of differential syndromes in different individuals and provides new ideas to help explain the essence of TCM syndromes in a microscopic view.

In the present study, there were shared and specific differentially expressed mRNAs in the healthy control group and both syndrome groups. Shared mRNAs may be related to the progression of HIV/AIDS, while specific genes may play a significant role in the formation of TCM syndromes in HIV/
AIDS. Massive abnormal apoptosis of T cells plays a critical role in HIV infection and immunopathogenesis of AIDS. HIV evasion and induction of lymphocyte apoptosis are the main reasons for the induction of AIDS progression. ${ }^{31-33}$

In the present study, differentially expressed mRNAs were found in two TCM syndrome groups; BCL2A1, IL1B, TNFAIP3, PTGS2, and NFKBIA were related to cellular apoptosis and regulation of apoptosis. Nuclear factor $-\kappa B$ $(\mathrm{NF}-\kappa \mathrm{B})$ participates in the proliferation and apoptosis of lymphocytes, ${ }^{34,35}$ while $B C L 2 A 1$ is a target gene in the inflammatory response that is induced by transcribed $N F-\kappa B$ and plays an important role in activation and survival of lymphocytes. ${ }^{36,37}$ Family members of BCL can help B cells in patients with HIV/AIDS evade elimination by Fas-mediated

Table 13. Twenty-five Genetic Expression Close to the Healthy Control Group IN THE DAMPNESS-HEAT RETENTION GROUP

\begin{tabular}{lcccc}
\hline Probe set ID & Gene symbol & After vs. healthy & Before vs. healthy & After vs. before \\
\hline 213524_s_at & GOS2 & 0.2021 & 0.024449 & 6.1832 \\
202859_x_at & $I L 8$ & 0.1932 & 0.036015 & 0.162281 \\
201502_s_at & NFKBIA & 0.4464 & 0.230006 & 2.6321 \\
243296_at & NAMPT & 0.6436 & 0.115045 & 2.5917 \\
204748_at & PTGS2 & 0.3259 & 0.176858 & 2.5699 \\
223217_s_at & NFKBIZ & 0.4537 & 0.253299 & 2.2493 \\
243509_at & - & 0.619 & 0.280119 & 2.2321 \\
201041_s_at & DUSP1 & 0.6134 & 0.208313 & 2.1092 \\
205681_at & BCL2A1 & 0.4517 & 0.190931 & 1.0323 \\
223218_s_at & NFKBIZ & 0.4019 & 0.310985 & 1.6559 \\
230333_at & - & 0.6397 & 0.317318 & 1.6488 \\
211998_at & H3F3B & 0.5456 & 0.393698 & 1.5412 \\
210592_s_at & SAT1 & 0.63 & 0.258998 & 2.8924 \\
236495_at & - & 0.6729 & 0.396169 & 1.8565 \\
232304_at & PELI1 & 0.7174 & 0.663453 & 1.8313 \\
212341_at & YIPF6 & 1.3195 & 0.520437 & 1.6856 \\
230529_at & HECA & 0.8578 & 0.490776 & 1.5987 \\
201531_at & ZFP36 & 0.8175 & 0.485686 & 1.592 \\
241133_at & TRBV27 & 0.7664 & 0.565384 & 1.5907 \\
204115_at & GNG11 & 0.8588 & 0.422807 & 1.5785 \\
212130_x_at & EIF1 & 0.6802 & 0.472423 & 1.5615 \\
204838_s_at & MLH3 & 0.7652 & 0.43391 & 1.5512 \\
202021_x_at & EIF1 & 0.6741 & 0.436141 & 1.5406 \\
212227_x_at & EIF1 & 0.6856 & 0.486319 & 1.5082 \\
217783_s_at & YPEL5 & 0.7626 & & \\
\hline
\end{tabular}


Table 14. Pathways of Genetic Expression Close to the Healthy Control Group in the Dampness-Heat Retention Group

\begin{tabular}{lccll}
\hline Pathway & Count & p-Value & q-Value & Gene symbol \\
\hline Systemic lupus erythematosus & 3 & $3.34 \mathrm{E}-05$ & $9.53 \mathrm{E}-06$ & H3F3B, LOC644914, H3F3A \\
Epithelial cell signaling in H pylori infection & 2 & $4.30 \mathrm{E}-04$ & $6.61 \mathrm{E}-05$ & IL8, NFKBIA \\
Small cell lung cancer & 2 & $6.48 \mathrm{E}-04$ & $9.25 \mathrm{E}-05$ & NFKBIA, PTGS2 \\
Toll-like receptor signaling pathway & 2 & $9.09 \mathrm{E}-04$ & $1.21 \mathrm{E}-04$ & IL8, NFKBIA \\
Mismatch repair & 1 & 0.009997 & $3.69 \mathrm{E}-04$ & MLH3 \\
Nicotinate and nicotinamide metabolism & 1 & 0.010429 & $3.69 \mathrm{E}-04$ & NAMPT \\
Urea cycle and metabolism of amino groups & 1 & 0.012157 & $4.12 \mathrm{E}-04$ & SATI \\
Bladder cancer & 1 & 0.018183 & $5.77 \mathrm{E}-04$ & IL8 \\
Arachidonic acid metabolism & 1 & 0.024601 & $7.34 \mathrm{E}-04$ & PTGS2 \\
Adipocytokine signaling pathway & 1 & 0.028857 & $8.49 \mathrm{E}-04$ & NFKBIA \\
B cell receptor signaling pathway & 1 & 0.032249 & $9.07 \mathrm{E}-04$ & NFKBIA \\
Chronic myeloid leukemia & 1 & 0.032249 & $9.07 \mathrm{E}-04$ & NFKBIA \\
VEGF signaling pathway & 1 & 0.032672 & $9.07 \mathrm{E}-04$ & PTGS2 \\
Prostate cancer & 1 & 0.037737 & $9.91 \mathrm{E}-04$ & NFKBIA \\
Apoptosis & 1 & 0.038158 & $9.91 \mathrm{E}-04$ & NFKBIA \\
T cell receptor signaling pathway & 1 & 0.046541 & 0.001029 & NFKBIA \\
Cytokine-cytokine receptor interaction & 1 & 0.108409 & 0.001792 & IL8 \\
MAPK signaling pathway & 1 & 0.113486 & 0.00183 & DUSP1 \\
\hline
\end{tabular}

Gene expression in HIV/AIDS patients with the dampness-heat retention syndrome before and after intervention was compared. After intervention, 25 differentially expressed genes that involved 16 signaling pathways progressed toward the healthy control group $(p<0.05)$. Compared with the results seen in the qi-yin deficiency syndrome group, both syndromes had both similar and different pathways, and normalized genes that were present in both syndromes were not all the same.

cell death. $^{38,39}$ In addition, NFKBIA (NF- $\kappa \mathrm{B}$ inhibitor $\left.\alpha\right)$ encodes a protein that blocks NF- $\kappa \mathrm{B} .{ }^{40}$ After TCM intervention, BCL2A1, NFKBIA, and PTGS2 tended to normalize. Different expression of these genes plays a certain role in apoptosis of immune cells in patients with HIV/AIDS. ${ }^{41}$ Prognosis after intervention initially verified that therapeutics might be effective in situations where altered gene expression is evident.

As the research on the relationships of HIV infection with chemokines and immune response has deepened, some chemokine receptors have been shown to be related to HIV1 infection. ${ }^{42-45}$ When infected with HIV, chemotactic factors such as CXCR4 and CCR5 can cause apoptosis upon interacting with the envelope glycoprotein gp120 of HIV-1, permitting entry of the virus into viable $\mathrm{T}$ lymphocytes. $^{46}$ In the present study, differentially expressed genes relevant to chemokine and immune response pathways, such as $I L 1 B, I L 8$, and NFKBIA, were detected. Secreted by many kinds of cells in the inflammatory response, interleukin (IL)-8 can induce inflammatory responses of chemokines and participate in neutrophil activation. ${ }^{47,48}$ The content of IL- 8 and tumor necrosis factor- $\alpha$ increased when mononuclear cells of healthy individuals were infected with HIV in the early stages of disease. ${ }^{48}$ The IL-1 family can regulate the inflammatory response, while polymorphisms in the IL-1B family were significantly associated with HIV-1 infection. ${ }^{50}$

In the present study, unlike in the early stages of monocyte infection, downregulated expression of IL-8 and IL-1B were related to dysfunction of immune cells caused by long-term infection with HIV. In addition, $N F K B I A$ is the regulatory hub for genetic transcription related to many immune-mediated inflammatory processes through the NF$\kappa \mathrm{B}$ pathway. ${ }^{51,52}$ After treatment, IL8, ILIB, and NFKBIA became normalized, indicating that therapeutics can influence the expression of these genes.

AIDS is a chronic immune deficiency disorder, and qi-yin deficiency syndrome is one of the common deficiency syndromes in AIDS. Different TCM syndromes have different pathologies, and differentially expressed genes in both syndromes have their own specificities.

Through comparison of differentially expressed mRNA in both syndromes, the enrichment score of apoptosis for mRNA downregulated in the qi-yin deficiency syndrome group was lower than the score in the dampness-heat retention syndrome group. In addition, the mRNA that was involved in apoptosis and upregulated in the qi-yin deficiency syndrome group was found through functional annotation clustering. CCR2, CD274, and TNFSF10 were expressed differentially in the qi-yin deficiency syndrome group but showed no obvious changes in the dampness-heat retention syndrome group.

It was believed that polymorphism of CCR2 was related to host immunity, sensitivity to HIV-1 infection, and progression of disease. ${ }^{53}$ The interactions between CD274 (B7 H1) and programmed cell death factor 1 can inhibit immune responses of $\mathrm{T}$ cells by inhibiting the proliferation of $\mathrm{T}$ cells and the generation of cell factor. ${ }^{54,55}$ The enrichment score for negative regulation of cellular activity and communication downregulated in the qi-yin deficiency syndrome group was greater than that in the dampness-heat retention syndrome group. The pathway of the differentially expressed mRNAs in the two different syndromes showed that differential expression related to chemokines and cellular factors was more obvious in the qi-yin deficiency group.

The results of immune functional analyses showed that compared with the dampness-heat retention group and healthy control group, the absolute value of $\mathrm{CD}^{+}$and $\mathrm{CD} 8^{+}$ 


\section{a}

** $\quad$ ****

*⿻ㅜㄴ

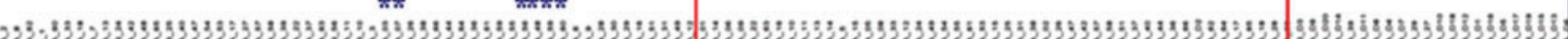

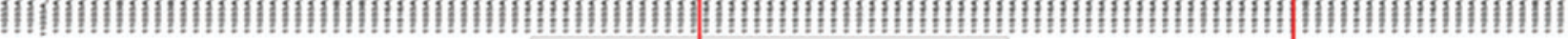

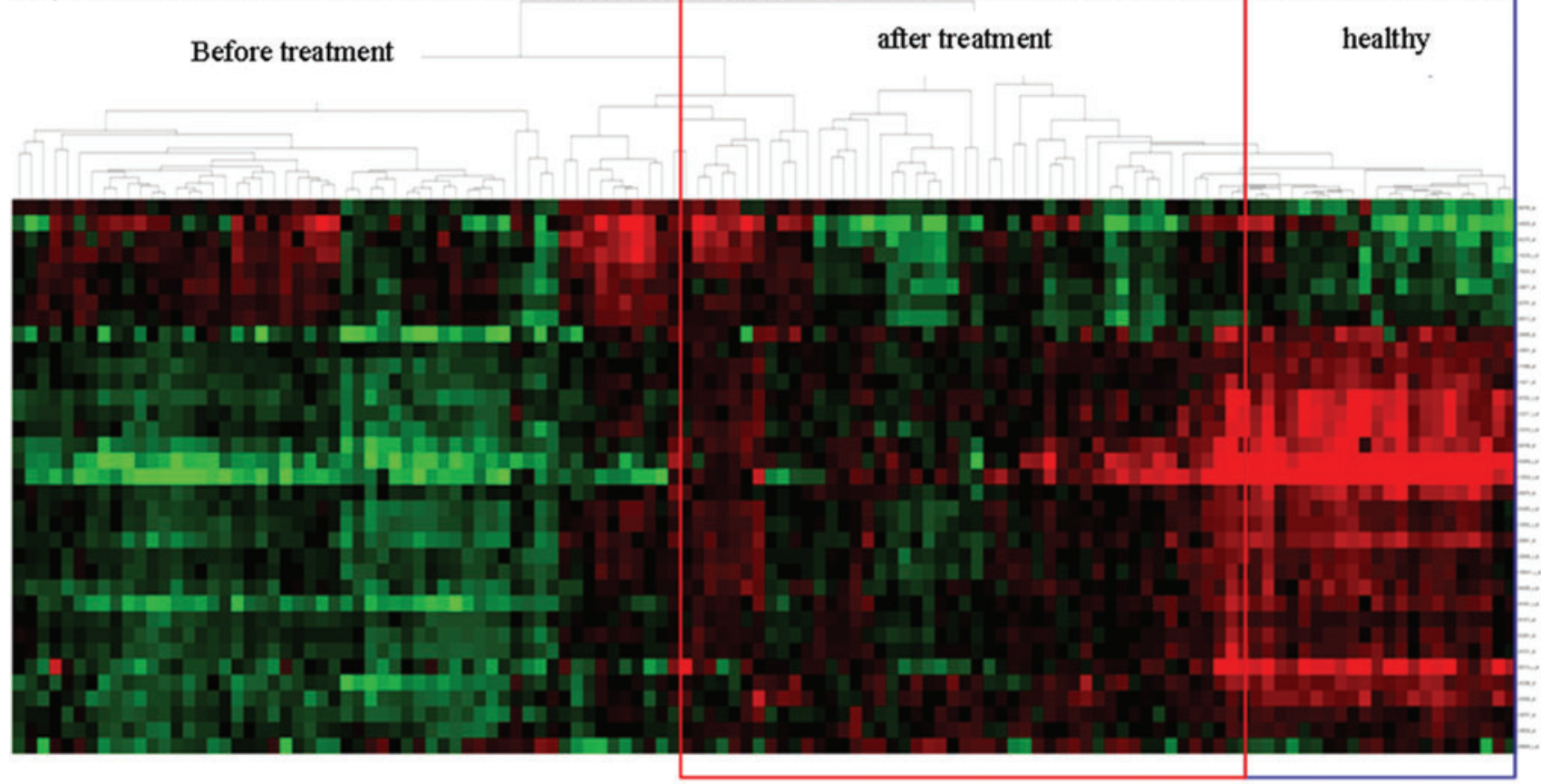

*Wrong points of before treatment; Wrong points of after treatment

b

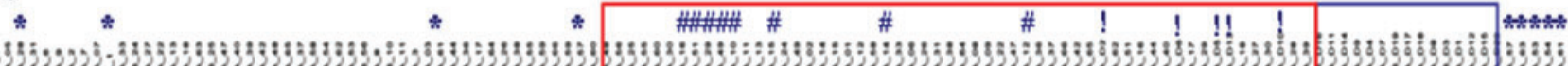

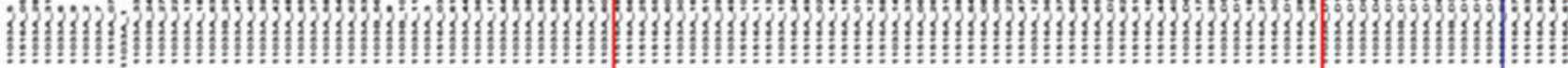

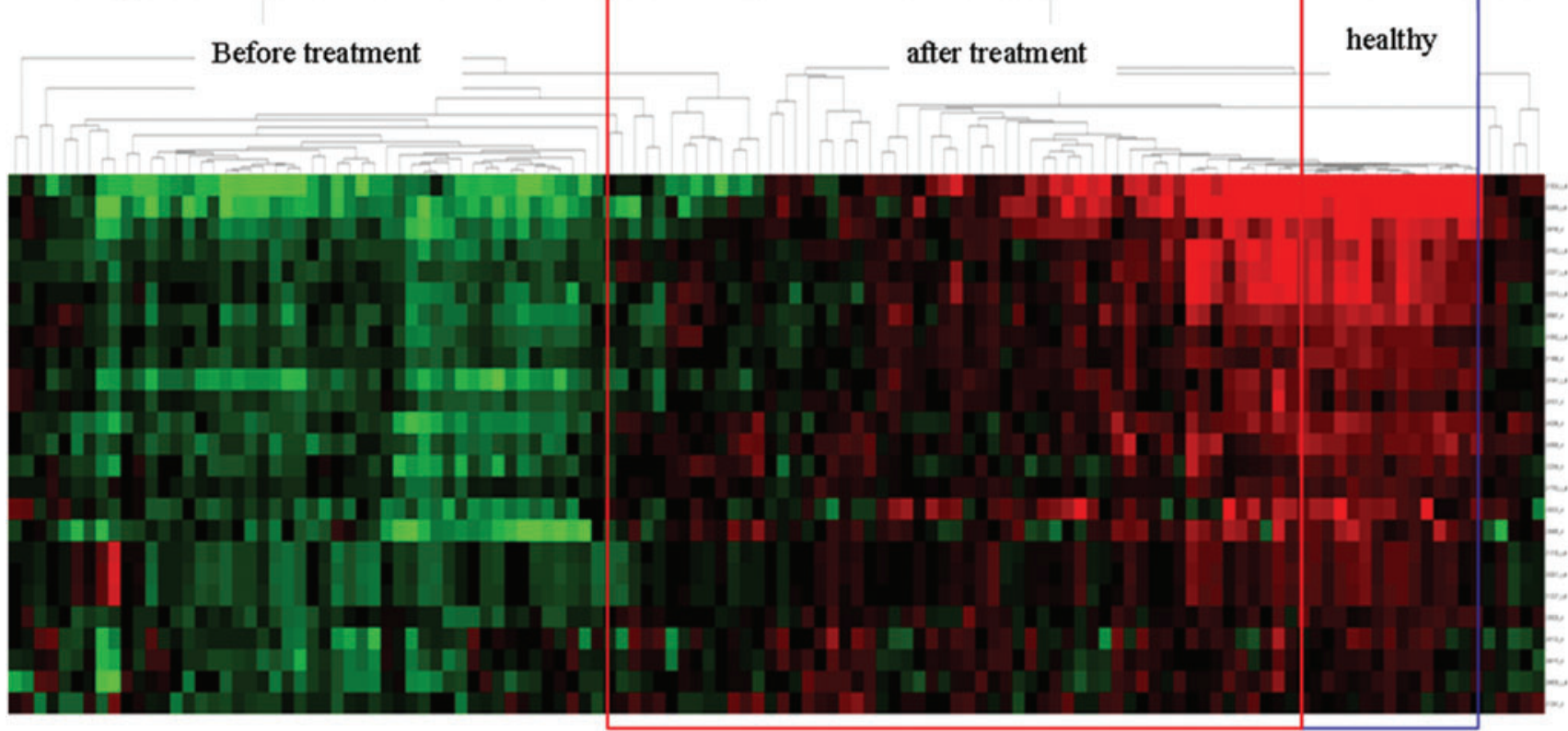

*Wrong points of before treatment;\#Wrong points of after treatment;!Wrong points of healthy

FIG. 6. With BRB-Array Tools version 4.2, mRNAs in both syndromes before and after treatment and in the healthy group were analyzed by hierarchical clustering. Red represents the increase in genetic expression levels, while green represents a decrease in expression. In the qi-yin deficiency syndrome (a), some samples were misclassified into the priortreatment disease group and the normal control group by following the intervention. Misclassification into prior treatment, post-treatment, and normal samples was also found in the dampness-heat retention group (b). After treatment, both syndrome groups were closer to the control group, and the expression levels of differentially expressed genes was normalized. Color images available online at www.liebertpub.com/acm 
$\mathrm{T}$ cells was smaller in the qi-yin deficiency group. This finding indicated that patients with HIV/AIDS and qi-yin deficiency had more severe immune damage. According to other studies in the field, inflammation and genetic polymorphism of cellular factors were related to fatigue in adults with HIV/AIDS. ${ }^{56}$ The pathological mechanism still requires further study and remains largely unresolved.

The dampness-heat retention syndrome is one of the commonly seen excess syndromes in AIDS. Some scholars found that the activity of cellular factors, apoptosis and proliferation regulation had changed in patients with hepatitis and those with gastritis who had dampness-heat retention. ${ }^{57,58}$ Downregulated genes that were related to cell composition, cell apoptosis, and lymphocyte activation and upregulated genes that were related to cell composition were detected in the dampness-heat retention group. These genes may be associated with dampness-heat retention symptoms, such as diarrhea and bitter and sticky mouth. It was found that $36 \%-56 \%$ of hospitalized patients with AIDS had hyponatremia and $16 \%-24 \%$ of patients had hyperkalemia. ${ }^{59}$ In the dampnessheat retention patients, upregulated genes were involved in potassium ion transport

By classification and prediction of differentially expressed genes in both syndrome groups, seven mRNAs were screened. The findings showed that these seven mRNAs may be the biological basis of both syndromes; this result was significant in the context of the differentiation of TCM syndromes in terms of genetic expression. The interaction diagram of differentially expressed mRNAs of both syndromes showed that these differentially expressed mRNAs were related to each other, forming a complex informational network. The correlations of differential mRNAs also differed between both syndromes, which indicated that these genes played an important role in patients with AIDS presenting with different syndromes.

\section{Conclusions}

Through testing the expression profiles of total RNA in the peripheral blood of patients with HIV/AIDS who had qiyin deficiency and dampness-heat retention, the present study predicted in an exploratory way that an inherent biological basis might have been responsible for the TCM syndromes in these patients. Further, the functions of differentially expressed mRNAs and their pathways might also be related to the formation of two common syndromes in patients with HIV/AIDS, which provides a useful reference point for further research on the inherent complexities of TCM syndromes in AIDS.

\section{Acknowledgments}

The authors thank all the patients and healthy donors. This work was supported by the National Science and Technology Major Project of China (2009ZX10005-021, 2012ZX10005001-005) from the Ministry of Science and Technology of People's Republic of China, National Natural Science Foundation of China (81403342) and sponsored by Program for Science \& Technology Innovation Talents in Universities of Henan Province (16HASTIT031). They also thank Zhao Wang, professor in the College of Life Science, Tsinghua University, for guidance and cooperation.

\section{Author Disclosure Statement}

No competing financial interests exist.

\section{References}

1. Mbita Z, Hull R, Dlamini Z. Human immunodeficiency virus-1 (HIV-1)-mediated apoptosis: new therapeutic targets. Viruses 2014;6:3181-3227.

2. Dybul M, Fauci AS, Bartlett JG, et al. Guidelines for using antiretroviral agents among HIV-infected adults and adolescents. Ann Intern Med 2002;137:381-433.

3. Liu A, Li J, Ye J, et al. Clinical observation of efficacy and safety of second-line antiretroviral therapy in HIV/AIDS. Chin J AIDS STD 2015;2:450-452.

4. Mikhail IS, DiClemente R, Person S, et al. Association of complementary and alternative medicines with HIV clinical disease among a cohort of women living with HIV/AIDS. J Acquir Immune Defic Syndr 2004;37:1415-1422.

5. Owen-Smith A, Diclemente R, Wingood G. Complementary and alternative medicine use decreases adherence to HAART in HIV-positive women. AIDS Care 2007; 19:589-593.

6. Dhalla S, Chan KJ, Montaner JS, et al. Complementary and alternative medicine use in British Columbia-a survey of HIV positive people on antiretroviral therapy. Complement Ther Clin Pract 2006;12:242-248.

7. Wang J, Liang B, Zhang X, et al. An 84-month observational study of the changes in CD4 T-lymphocyte cell count of $110 \mathrm{HIV} / \mathrm{AIDS}$ patients treated with traditional Chinese medicine. Front Med 2014;8:362-367.

8. Zhao HX, Zhang FJ, Han N, et al. [Effects of traditional Chinese medicine on CD4+ T cell counts and HIV viral loads during structured treatment interruption in highly active antiretroviral therapy]. Zhongguo yi xue ke xue yuan xue bao. Acta Academiae Medicinae Sinicae 2006;28: 658-661.

9. Chen X, Yang Z, Shen F, et al. Curative effect of fufang qizhu tang in pixu (spleen deficient) syndrome of patients with HIV/AIDS and the influence of CD4 T lymphocytes in peripheral blood. Acta Universitatis Traditionis Medicalis Sinensis Pharmacologiaeque Shanghai 2010;24:40-42.

10. Chen R, Snyder M. Systems biology: personalized medicine for the future? Curr Opin Pharmacol 2012;12:623-628.

11. Niu X. Discussion on the application of molecular biology techniques in the research of TCM Syndrom. Chin J Basic Med Trad Chinese Med 2014;20:1510-1512.

12. $\mathrm{Wu} \mathrm{M}, \mathrm{Wu} \mathrm{M}$. Correlation of molecular biology techniques and disease of TCM syndromes studies. J Trad Chin Med 2002;43:8-10.

13. Xu Q, Yan X, Wu X. Transcriptomics in the fight against AIDS medicine TCM syndrome research applications. China J Chin Med 2014;29:309-311.

14. Li X, Liang Y, Li J, et al. Research of systems biology and the essence of TCM syndrome. Chin J Basic Med Trad Chin Med 2011;17:211-212.

15. Xie S, Zuo G. Use of systems biology in research of TCM syndromes. World Chin Med 2011;6:369-371.

16. Zhang A, Sun H, Wang P, et al. Future perspectives of personalized medicine in traditional Chinese medicine: a systems biology approach. Complement Ther Med 2012;20: 93-99.

17. Li YP, Zhao Y, Deng JG. Development and analysis on TCM treatment on experimental research on HIV /AIDS animals. Jilin J Trad Chin Med 2014;34:993-995. 
18. Zhang XW. Research progress on HIV/AIDS treatment with traditional Chinese medicine. Chin Med Modern Distance Educ China 2008;6:86-88.

19. Yan SL, Shen HC, Wang HZ, et al. Research to three kinds of disease kidney yang syndrome. "Treating same syndrome with different method" at signal transduction pathways. J Yunnan Coll Trad Chin Med 2012;35:5-9.

20. Yang C, Liu H, Wang L. Study on the differential gene expressions of chronic hepatitis B patients of gan depression pi deficiency syndrome and pi-wei damp-heat syndrome. Chin J Integr Trad Western Med 2012;32:10321037.

21. Li MD, Cao J, Wang S, et al. Transcriptome sequencing of gene expression in the brain of the HIV-1 transgenic rat. PloS One 2013;8:e59582.

22. Xu WW, Han MJ, Chen D, et al. Genome-wide search for the genes accountable for the induced resistance to HIV-1 infection in activated CD4+ T cells: apparent transcriptional signatures, co-expression networks and possible cellular processes. BMC Med Genom 2013;6:15.

23. Qiu H, Xie SP, Guo XX. Epidemiology distribution of TCM syndromes of 274 patients with HIV/AIDS. J Zhengzhou Univ Med Sci 2007;42:363-364.

24. Li Q, Wang YL, Wang YH. Epidemiology and TCM syndrome type distribution of 168 patients with HIV/AIDS. Fujian J Trad Chin Med 2007;38:4-6.

25. Qin GZ, Li QS, Zhang CH. Disease occurrence characteristics of TCM and database established of TCM syndromes study of AIDS. J Yunnan Coll Trad Chin Med 2008;2: 43-45.

26. Shi X. Statistical Modeling of AIDS Syndromes. Guangzho, China: Guangzhou University of Chinese Medicine, 2008.

27. Chen XH. Quantitative Study of Common Excess Syndrome of AIDS. Zhengzhou, China: Henan University of Traditional Chinese Medicine, 2008.

28. Xu QL, Wu XW, Xie SP, et al. Study on standardization research of AIDS traditional Chinese medicine syndromes. Chin J Exp Trad Med Form 2012;17:096.

29. Deng ZJ. Pharmacology of traditional Chinese medical formulae. China Pr Trad Med 2007;10:156.

30. Lin PZ. Science of seasonal febrile disease. China Pr Trad Med 2007;1:218.

31. Yue FY, Kovacs CM, Dimayuga RC, et al. Preferential apoptosis of HIV-1-specific CD4+ T cells. J Immunol 2005;174:2196-2204.

32. Sperber K, Beuria P, Singha N. Induction of apoptosis by HIV-I-infected monocytic cells. J Immunol 2003;170: 1566-1578.

33. Derks RA, Beaman KD. Regeneration and tolerance factor prevents bystander $\mathrm{T}$-cell death associated with human immunodeficiency virus infection. Clin Diagnost Lab Immunol 2004;11:835-840.

34. Chen F, Castranova V, Shi X. New insights into the role of nuclear factor-kappaB in cell growth regulation. Am J Pathol 2001;159:387-397.

35. Fiume G, Vecchio E, De Laurentiis A, et al. Human immunodeficiency virus-1 Tat activates NF-kappaB via physical interaction with IkappaB-alpha and p65. Nucleic Acids Res 2012;40:3548-3562.

36. Herman MD, Nyman T, Welin M, et al. Completing the family portrait of the anti-apoptotic Bcl-2 proteins: crystal structure of human Bfl-1 in complex with Bim. FEBS Lett 2008;582:3590-3594.
37. Barshack I, Lithwick-Yanai G, Afek A, et al. MicroRNA expression differentiates between primary lung tumors and metastases to the lung. Pathol Res Pract 2010;206:578-584.

38. Rothstein TL. Inducible resistance to Fas-mediated apoptosis in B cells. Cell Res 2000;10:245-266.

39. Patro SC, Pal S, Bi Y, et al. Shift in monocyte apoptosis with increasing viral load and change in apoptosis-related ISG/Bcl2 family gene expression in chronically HIV-1infected subjects. J Virol 2015;89:799-810.

40. Klein W, Tromm A, Folwaczny C, et al. A polymorphism of the NFKBIA gene is associated with Crohn's disease patients lacking a predisposing allele of the CARD15 gene. Int J Colorectal Dis 2004;19:153-156.

41. Wang JH, Wang YY, Ouyang DY, et al. Apoptosis in human immunodeficiency virus infection. Zoologic Res 2002; 23:514-520.

42. Feng $\mathrm{Y}, \mathrm{Hu} \mathrm{J}$, Ma J, et al. RNAi-mediated silencing of VEGF-C inhibits non-small cell lung cancer progression by simultaneously down-regulating the CXCR4, CCR7, VEGFR-2 and VEGFR-3-dependent axes-induced ERK, p38 and AKT signalling pathways. Eur J Cancer 2011;47: 2353-2363.

43. Oswald-Richter K, Grill SM, Leelawong M, et al. Identification of a CCR5-expressing $\mathrm{T}$ cell subset that is resistant to R5-tropic HIV infection. PLoS Pathogens 2007; 3:e58.

44. Hutter G, Nowak D, Mossner M, et al. Long-term control of HIV by CCR5 Delta32/Delta32 stem-cell transplantation. N Engl J Med 2009;360:692-698.

45. Ruibal-Ares BH, Belmonte L, Bare PC, et al. HIV-1 infection and chemokine receptor modulation. Curr HIV Res 2004;2:39-50.

46. Catani MV, Corasaniti MT, Navarra M, et al. gp120 induces cell death in human neuroblastoma cells through the CXCR4 and CCR5 chemokine receptors. J Neurochem 2000;74:2373-2379.

47. Bi HJ, Wang J. Expression of CXCR1, CXCR2 and EL-8 in Peripheral Blood of Liver Cirrhosis Patients. Anhui Province, China: Anhui University of Science \& Technology, 2012;5:1-21.

48. Glienke W, Esser R, von Briesen H, et al. Cytokine expression of HIV-infected monocytes/macrophages at the single-cell level. Res Virol 1994;145:193-197.

49. Conaldi PG, Serra C, Dolei A, et al. Productive HIV-1 infection of human vascular endothelial cells requires cell proliferation and is stimulated by combined treatment with interleukin-1 beta plus tumor necrosis factor-alpha. J Med Virol 1995;47:355-363.

50. Pontillo A, Oshiro TM, Girardelli M, et al. Polymorphisms in inflammasome genes and susceptibility to HIV-1 infection. J Acquir Immune Defic Syndr 2012;59:121-125.

51. Koc A, Batar B, Celik O, et al. Polymorphism of the NFKB1 affects the serum inflammatory levels of IL-6 in Hashimoto thyroiditis in a Turkish population. Immunobiology 2014;219:531-536.

52. Ali S, Hirschfeld AF, Mayer ML, et al. Functional genetic variation in NFKBIA and susceptibility to childhood asthma, bronchiolitis, and bronchopulmonary dysplasia. J Immunol 2013;190:3949-3958.

53. Mhandire K, Duri K, Kandawasvika G, et al. CCR2, CX3CR1, RANTES and SDF1 genetic polymorphisms influence HIV infection in a Zimbabwean pediatric population. J Infect Developing Countries 2014;8:13131321. 
54. Deng R, Cassady K, Li X, et al. B7H1/CD80 interaction augments PD-1-dependent T cell apoptosis and ameliorates graft-versus-host disease. J Immunol 2015;194:560-574.

55. Ostrand-Rosenberg S, Horn LA, Haile ST. The programmed death-1 immune-suppressive pathway: barrier to antitumor immunity. J Immunol 2014;193:3835-3841.

56. Lee KA, Gay CL, Lerdal A, et al. Cytokine polymorphisms are associated with fatigue in adults living with HIV/AIDS. Brain Behav Immun 2014;40:95-103.

57. Li HF, Liu Y, Luo BD. Expression of NF-kB in liver of hepatitis-virus febrile disease dampness-heat syndrome model mice. J New Chin Med 2012;44:152-154.

58. Xing H, Lao S. Expression of IL-8 and HsP70 in HPRelated Gastropathy Spleen-Stomach Damp-Heat Syn- drome. Guangzhou, China: Guangzhou University of Chinese Medicine, 2009;4:9-12.

59. Zhang XQ, J. F. HIV Virus and AIDS. Beijing: People's Medical Publishing House, 1999.

Address correspondence to: Shiping Xie, $M D$ Department of Clinical Foundation of TCM Henan University of TCM Zhengzhou 450046 China

E-mail:xspzz@126.com 